\title{
DIFFERENCES IN BUSINESS RISK EFFECTS ON THE FUTURE OF SMEs DUE TO THE COVID-19 PANDEMIC
}

\author{
Ján Dvorský \\ Tomas Bata University in Zlín, Faculty of Management and Economics, Department of Business \\ Administration, Zlin, Czech Republic \\ Email: j1dvorsky@utb.cz \\ Martin Čepel \\ University of Entrepreneurship and Law, Department of Marketing, Prague, Czech Republic \\ Email: martin.cepel@vspp.cz \\ Anna Kotásková \\ University of Entrepreneurship and Law, Department of Marketing, Prague, Czech Republic \\ Email: anna.kotaskova@,vspp.cz
}

Katarína Bugánová

University of Žilina, Faculty of security engineering, Department of Crisis management, Žilina, Slovak Republic Email: katarina.buganova@,fbi.uniza.sk

Received: 12 September 2021. Revision received: 25 October 2021. Accepted: 14 November 2021

\begin{abstract}
The article aims to identify, analyze, and quantify disparities in the impact of entrepreneurial risks on the future of small and medium-sized enterprises in the business environment of the Czech Republic in light of the COVID-19 pandemic. The research was carried out on 814 SMEs in two phases. 454 SMEs participated in the first phase of the research, which took part before the COVID-19 pandemic. 360 SMEs took part in the second research phase during the pandemic. Statistical methods such as correlation analysis and linear regression modeling were applied to evaluate statistical hypotheses. The results yielded interesting findings. According to respondents, the three most significant business risks in the SME segment include market, financial, and personnel risk in the period before the COVID-19 pandemic and during the COVID-19 pandemic. Prior to the COVID-19 pandemic, entrepreneurs saw the adequacy of sales and financial performance of the business as key determinants that impact the future of SMEs over a 5-year horizon. Conversely, during the COVID-19 pandemic, entrepreneurs perceived the management of the company's personnel performance, financial performance, and ability to manage financial risk as determinants that affect the future of SMEs over five years. According to owners and top managers during the COVID-19 pandemic, the most significant factor is the adequacy of personnel risk in SMEs. On the one hand, the findings benefit the owners themselves and the top managers of SMEs. On the other hand, government institutions and organizations that decide on government measures promote a penetrating environment. Also, the non-profit sector (e.g. Association of Small and Medium-Sized Enterprises and Crafts of the Czech Republic) assists SMEs in their edible activities and activities.
\end{abstract}

KEYWORDS: SMEs, business risks, differences, COVID-19, business future.

JEL CLASSIFICATION: M21, G32, L26.

Reference: Dvorský, J., Čepel, M., Kotásková, A. \& Bugánová, K. (2021). Differences in business risk effects on the future of SMEs due to Covid-19 pandemic. International Journal of Entrepreneurial Knowledge, 9(2), 14-31. doi: 10.37335/ijek.v9i2.144

\section{INTRODUCTION}

The covid-19 pandemic is the source of many research activities by various authors, as it has affected a number of areas. Changes in behavior and risk management can also be observed in the business environment. Massive financial support from the main representatives of countries to save businesses from their collapse is mainly directed to the SME segment (Rodrigues et al., 2021; Dvorský et al., 2020). 


\section{INTERNATIONAL JOURNAL OF ENTREPRENEURIAL KNOWLEDGE}

Issue 9, volume 2, ISSN 2336-2960 (Online)

www.ijek.org

This is because SMEs are in themselves sensitive to economic, legislative, market changes (Mura \& Hajduová, 2021) in ambient behavior (e.g. customers, suppliers, buyers, government measures, legislative changes, etc.). As a result, SME owners and senior managers had to make strategic decisions on the existence of a business within a short period of time (Cepel et al., 2020). The most negatively affected business fields are services (Belas et al., 2020; Godany \& Mura, 2021), tourism (Machova et al., 2021), and the gastronomy industry. On the other hand, several authors also point to the positive changes in the business environment (accelerating innovations, digitalization in particular; Klein \& Todesco, 2021) and the growth of selected business sectors (e.g. IT industry; Rai et al., 2021; Rozsa \& Machova, 2021).

The business environment in the Czech Republic is specific in that, on the one hand, it is closely linked to the business environment of the surrounding countries (Germany, Slovak Republic - automotive industry and subcontractors; Hoeft, 2021). However, on the other hand, there is substantial demand for domestic products (especially in the agricultural sector; Korauš et al., 2020).

Several case studies claim that key business risks include risks associated with the sales of their products (Zhou et al., 2021); financial performance of the business (Ganlin et al., 2021), and human capital in the company (Mikołajczak, 2021). SEM owners consider human capital as the driving force of their business (e.g. Niciejewska et al., 2021). Entrepreneurs had to reduce their expenditure due to lower demand (due to anti-pandemic measures) for their products or services. Managing business risks in the current COVID-19 pandemic plays an important role in the direction and performance of SMEs (Grondys et al., 2021) and emphasizes management experience (Mihai, 2021) and knowledge of SME owners or top managers.

The case study maps changes in the perception of and effect of the key business risks (market, financial, and personnel risk) on the future of SMEs over the medium-term horizon of 5 years, given the negative impact of the COVID-19 pandemic on the business environment. The results are unique in the risk mapping at the peak of economic growth (9/2019-3/2020) and during the first wave of the COVID-19 pandemic (5/2020) in the SME segment of the business environment in the Czech Republic.

The article consists of a sequence of logical and successive parts. The first part features up-to-date findings of the effects of the COVID-19 pandemic on the business environment in selected countries, emphasizing the SME segment. The critical research also deals with business risks (market, financial, and personnel risk). Consequently, the aim, methodology of SME selection files before and during the COVID-19 pandemic are defined, and statistical hypotheses and methods are defined for their evaluation. The results include the evaluation process and the decisions to accept the hypotheses themselves. Finally, the discussion summarizes the most significant findings of the case study, which are confronted with current scientific findings in the world. The conclusion includes, but is not limited to, the limitations of the case study, formulates the potential and possibilities of applying these findings in the business environment of SMEs in the Czech Republic; and indicates the further direction of the authors' research activities.

\section{THEORETICAL BACKGROUD}

The COVID-19 pandemic has had a significant impact on European and non-European businesses. Millions of businesses lost their planned revenues and millions of jobs were compromised (Wei et al., 2021). The economic mechanism does not allow processes to stop without impacting the future of businesses, and when the economy stops, many business connections cease temporarily or permanently. The crisis also has a dramatic socio-economic impact, as a large part of the population becomes poor, is unable to pay the cost of living, loses jobs and real estate, which leads to health issues and depression, 


\section{INTERNATIONAL JOURNAL OF ENTREPRENEURIAL KNOWLEDGE}

Issue 9, volume 2, ISSN 2336-2960 (Online)

www.ijek.org

increasing the mortality on a global scale. Individual problems become a problem for the society as a whole.

The Czech Republic is an open economy, and it is therefore essential that business connections between businesses and business partners not be abolished. Although international demand is slowly recovering, it is essential that businesses are able to immediately resume production and return to their previous routine. Many businesses will no longer be able to do so. The pandemic crisis has affected the development of the global economy and threatened businesses around the world, as all economies have been disrupted with fatal consequences.

Literature on the economic impacts of the COVID-19 pandemic is in a rapid state of expansion (e.g. Rodrigues et al., 2021). This is on: the impact of the pandemic on labor markets; use of real-time data to understand the impact and recovery from the pandemic; the importance of networks and the linking of sectoral shocks to the overall consequences; examining the differences between the demand-supply component of the pandemic shock and the sectoral redistribution it induces; examining the impact of COVID-19 on business failures; evaluation of the effectiveness of small business support programs (Core \& De Marco, 2020).

Rathore \& Khanna (2020) examined the impact of government interventions in India's manufacturing sphere during the COVID-19 crisis. The authors carried out primary research in SMEs to find out what business owners' expectations are during the crisis. The smallest companies considered the extraordinary government measures to be very strict. Up to $70 \%$ of these businesses said they would not survive the crisis after three months if the lockdown continued. In their study, Alves et al. (2020) even state that small businesses are very vulnerable to the crisis, but there are no instructions on how to deal with the long COVID-19 crisis. They carried out a qualitative analysis of small businesses in China after the outbreak of the virus. The authors found that the sudden decline in market demand had the strongest negative impact on small businesses in particular. At the same time, small and young enterprises are highly flexible in response to the crisis, mainly due to less bureaucracy and limited respect for social responsibility. During the pandemic, the examined companies adopted flexible human resources strategies, while using product diversification strategy, market research, and training improvement. Small businesses with a longer history and more experience in crisis resolution, operating mainly in regulated sectors, had a formal crisis plan and crisis strategies in place before the outbreak.

Wang (2016), same as Civelek et al. (2020), also looked at the companies' responses to the implementation of innovative marketing strategies. Their aim was to find out how Chinese businesses are innovating their marketing strategies, focusing mainly on innovative motivators and assessing the level of innovation based on cooperation. The results of the study have had interesting implications regarding the preparedness of businesses for similar crisis situations. Civelek et al. (2021) also studied the innovativeness of family-owned SMEs depending on their different characteristics. According to their results, SMEs' innovativeness differs depending on their size, industry, and area activity. On the other hand, the analyses confirmed the nonexistence of the differences in SMEs' innovativeness concerning succession involvement. Contrariwise, Ključnikov et al. (2021) found that global innovativeness does not differ depending on firms-owners/entrepreneurs' characteristics.

Fontrodona \& Muller (2020) addressed the issue of the impact of COVID-19 on SMEs in terms of corporate social responsibility. They draw attention to compliance with the ten principles of the Global Pact, which the authors consider to be an appropriate tool for assessing the level of consistency demonstrated by socially responsible societies during a pandemic. In addition to monitoring the impact of the pandemic on business operations through research teams, many countries have also used monitoring through their government institutions to obtain the most accurately relevant images of the situation in the business sector. Core \& De Marco (2021) highlight the importance of bureaucratic 


\section{INTERNATIONAL JOURNAL OF ENTREPRENEURIAL KNOWLEDGE}

Issue 9, volume 2, ISSN 2336-2960 (Online)

www.ijek.org

efficiency during the COVID-19 crisis and stress the need to establish appropriate mechanisms for setting up optimal administrative processes in times of crisis.

The strong institutional impact of managing the COVID-19 crisis and its consequences for the economy are apparent from the study by Redmond \& McGuinness (2020). They stress the role of the Economic and Social Research Institute.

Spain, as one of the most affected countries, viewed the political consequences of the COVID-19 crisis very sensitively, as shown by the Study of Miguel and the Collective (2020). The authors analyzed the unequal political and economic burden of the COVID-19 crisis in Spanish households and examined the extent to which knowledge of the pandemic crisis affected people's political beliefs and opinions. They also examined the extent to which knowledge of policies influenced political views in society. The authors stress the importance of information and knowledge on the evolution of the pandemic and how information is collected, as well as the level of complexity of information that helps shape views in society and the population.

During the COVID-19 pandemic, the importance of business decline is also changing. This is presented by the Morrison \& Saavedra study (2020) which claims that national policy makers must strive to minimize SME bankruptcies or reduce the financial impact of the COVID-19 pandemic on businesses by adopting appropriate measures or decrees (laws). The authors stress that decline and subsequent bankruptcy can be very costly for SMEs, which can discourage business owners from potentially starting a business again. The authors also present the importance of key political tools - the support of funding during the bridging periods. The government should provide bridging financing if the credit markets are non-functional. The importance of the functioning of courts is no less a significant factor in the process of a business declaring bankruptcy. Frequent changes in legislation contribute to the instability of the business environment. Virglerova et al. (2020) stated that more than 25\% of the addressed SMEs from Visegrad Group (research covered 1781 SMEs) perceive the legislative changes as too frequent. These changes can lead to the legal risk of the companies and to the mistrust in national policy.

The impact of the COVID-19 crisis on SMEs was also examined by Lu et al. (2020) who aimed to evaluate issues related to work recovery and corresponding political requirements. Their research sample consisted of 4807 SMEs in the Sichuan province, using surveys and online interviews as their research method. The majority of SMEs could not continue to operate due to lack of materials to mitigate the epidemic, inability of employees to return to work, disruption of supply chains, and reduced market demand. They cited cash flow risks due to many fixed expenses, but only low or no income, as the main risks to the survival of SMEs. This has put considerable pressure on the survival of SMEs. The study also serves as a call for recommendations on job recovery, stimulating consumption and freeing up cash flows.

Prohorovs (2020) presents the need for a clear understanding of the specificities of the COVID-19 crisis, so that businesses can adapt more quickly to the new harm reduction situation. The author compares the current economic recession caused by the COVID-19 pandemic with previous economic crises. As a business owner, he presents his own experience in reducing the business risk caused by the pandemic. The presented experience and recommendations should ensure the sustainability of SMEs in these difficult business conditions. Many other studies offer recommendations for the micro and macro spheres.

The financial aspects and research of relevant financial support instruments for SMEs during the pandemic are the theme of a study carried out by Levashenko \& Koval (2020). The authors argue that SMEs are much more exposed to pandemic than large companies are. They highlight the implementation and use of financial instruments such as direct financing, tax incentives, etc. According to the authors, the system of non-financial support is also important. Some research studies have examined the impact of the COVID-19 pandemic on different business sectors. 


\section{INTERNATIONAL JOURNAL OF ENTREPRENEURIAL KNOWLEDGE}

Issue 9, volume 2, ISSN 2336-2960 (Online)

www.ijek.org

The COVID-19 pandemic has not only resulted in an economic crisis, but also has significant social and environmental consequences that have seriously affected the tourism sector. It also presents important political implications linking sectoral political solutions to macroeconomic indicators. In some studies, the COVID-19 impact investigation has a strong geographical overtone, e.g. by Åslund (2020) who studied responses to the COVID-19 crisis in Russia, Belarus and Ukraine. These countries provide an appropriate basis for comparison because of their common Soviet past, similar culture and religion. However, during the COVID-19 crisis, these countries implemented completely different policies, which showed in their economic results. When examining these countries, the author makes appropriate comparisons in order to evaluate the impact of the implemented policies on countries' economic performance. He argues that the impact cannot currently be quantified, which will later be reflected in the key economic parameters of the countries.

Michie (2020) creates his own philosophical framework for assessing the impact of the COVID-19 crisis on national economies based on macroeconomic aspects. He asks whether the measures taken and preparations for the crisis discussed in advance are sufficient and how the recession will affect mortality and morbidity in the form of deterioration of physical and mental health, increased number of suicides, etc. The author states that politicians will always use economic arguments to defend their responses to the recession in order to introduce cost-efficient measures aimed at reducing the national debt, etc. This can lead to higher mortality rates in countries. Despite the diversified geographical orientation of economic policies and the different SME research samples, the above research studies provide valuable information on the SME segment and the challenges they face during the COVID-19 pandemic.

\section{DATA, METHODOLOGY AND METHODS}

The aim of the article is to identify, analyze and quantify differences in the impact of entrepreneurial risks on the future of SMEs in the business environment of the Czech Republic in the light of the COVID19 pandemic. Respondent is understood to be the top manager or owner of an SME in the business environment of the Czech Republic.

Data collection during the COVID-19 pandemic (hereinafter referred to as "during the pandemic") took place from September 1, 2019 to March 4, 2020. The 'Cribis' database was used to define the population of respondents and then to reach them. Information was obtained from the above-mentioned database: about the number of respondents in individual regions of the Czech Republic as of June 30, 2019. The process of applying the method of random selection of respondents from databases was as follows: the basic set of respondents was defined and determined according to the selected criterion (up to 249 employees) in the selected region of the Czech Republic; a serial number (alphabetically) was established for each respondent in the selected region of the Czech Republic; random numbers were generated using the mathematical function "Randbetween" (function range: smallest value -1 , largest value - the total number of respondents in the selected region of the Czech Republic at the selected date); respondents were assigned to randomly generated numbers in the selected region of the Czech Republic; a telephone or e-mail contact to the respondent was found. 8250 SMEs in the Czech Republic were contacted via email. To increase representability, between January 1, 2020 and March 4, 2020, respondents were contacted by phone asking if they had received a request to reply to the questionnaire and whether they had replied to it. Attitudes from respondents were obtained by the method of inquiry in the form of replying to an online questionnaire or a printed form of a questionnaire. The questionnaire is currently available on the Internet at the following link: https://forms.gle/okjZypAru4BpSHFb8. A total of 465 questionnaires were completed before the COVID-19 pandemic ('before the pandemic'). The number of correctly completed questionnaires was 454 (97.6\%). The number of incorrect questionnaire replies amounted to $11(2,4 \%)$. The most significant reasons for excluding the respondent from the sample: duplication of the questionnaire in the sample; consistency of the respondent's attitudes to business risk 


\section{INTERNATIONAL JOURNAL OF ENTREPRENEURIAL KNOWLEDGE}

Issue 9, volume 2, ISSN 2336-2960 (Online)

www.ijek.org

assessment; inattention of the respondent when filling in the questions which he/she should not have answered, etc.

Data collection during the COVID-19 pandemic (hereinafter referred to as "during the pandemic") was carried out by the research agency MNFORCE. The research agency currently has 121,000 registered panelists, more than 350,000 questionnaire replies for calendar year 2020 and more than 90 satisfied customers. MNFORCE operates in four countries: Austria, the Slovak Republic (hereinafter referred to as "SK"; according to ISO 3166-2, 2013), the Czech Republic, and Poland. Their significant customers include: ŠKODA AUTO Czech Republic; Slovnaft, a. s.; Slovanet; Zepter International, s.r.o. and others. More information is available on their website (https://www.mnforce.com/en/index.php). The main criterion for the sample of respondents was the same wording of the respondent as in the selection file of respondents before the pandemic (i.e. only the owner or top manager of the SME operating in the business environment of the Czech Republic can fill in the questionnaire).

Another criterion for the selection of respondents was the maximum number of self-employed people in the sample, which was set at 60\% (a figure supported by the ratio of self-employed to the total sample of respondents in the Czech Republic). The collection of attitudes from respondents took place from May 11, 2020 to May 17, 2020. The sample of respondents during the pandemic consisted of 360 respondents. The average time to complete the questionnaire was 11 minutes and 45 seconds.

\section{Table 1 Business risk sources}

\begin{tabular}{|l|l||}
\hline \multirow{3}{*}{$\begin{array}{c}\text { Independent } \\
\text { variables }\end{array}$} & $\begin{array}{l}\text { ST1: I consider the market risk (lack of sales for my business) to be reasonable. } \\
\text { ST2: Our company uses innovative ways of acquiring new markets and retain existing } \\
\text { customers. }\end{array}$ \\
\cline { 2 - 3 } & $\begin{array}{l}\text { ST3: I consider the financial performance of our (my) company to be positive. } \\
\text { ST4: I am able to appropriately manage financial risk in my (our) company. }\end{array}$ \\
\cline { 2 - 3 } & $\begin{array}{l}\text { ST5: I consider the personnel risk in the company to be reasonable and not having } \\
\text { a negative impact on my business. }\end{array}$ \\
\hline $\begin{array}{c}\text { Dependent } \\
\text { variable }\end{array}$ & BP: Our (my) company is not in danger of facing decline within the next 5 years. \\
\hline
\end{tabular}

(Source: Own data collection)

Statistical hypotheses (SHs) were formulated to achieve the aim of the paper:

$\mathrm{SH}$ : There is no statistically significant impact of the claim on: market risk $\left(\mathrm{SH}_{\mathrm{ST} 1}, \mathrm{SH}_{\mathrm{ST} 2}\right)$; financial risk $\left(\mathrm{SH}_{\mathrm{ST} 3}, \mathrm{SH}_{\mathrm{ST} 4}\right)$; personnel risk $\left(\mathrm{SH}_{\mathrm{ST} 5}\right)$ on the future of $\mathrm{SMEs}$ according to respondents before $(\mathrm{SHA})$ and during the pandemic (SHB) in the business environment of the Czech Republic, according to owners and top managers of SMEs.

Regression analysis (RA) was applied to evaluate H1 because RA is used to identify and quantify independent variables (selected business risks) and determine the direction and strength of the impact on the dependent variable (threat of business decline within 5 years). The examined variables (independent, dependent) are identical metrics (scaling responses: 1 - I fully agree, ..., 5 - I totally disagree). The arguments are also formulated in such a way that respondents' consenting attitudes on independent variables are directed towards consenting attitudes on the dependent variables (assumption of linearity). However, in order to apply the regression analysis, the prerequisites must be met. The resulting linear regression model (LRM) must not be negatively affected by multicolinearity and the assumptions about the random component of the time series (homoscedasticity and normal distribution) must also be met; Spanos \& McGuirk, 2002). Verification of the above assumptions about LRMs needs to be carried out in order for the estimated regression model coefficients to reflect the reality as authentically as possible. A correlation matrix with paired correlation coefficients was used to determine 


\section{INTERNATIONAL JOURNAL OF ENTREPRENEURIAL KNOWLEDGE}

Issue 9, volume 2, ISSN 2336-2960 (Online)

www.ijek.org

the dependency between the dependent variable and the independent variables. The paired correlation coefficient ( $\mathrm{r}$ ) can acquire values between -1 and 1 (Lancaster \& Hamdan, 1964). The statistical significance of the paired correlation coefficients has been verified by a t-test.

If the p-value of the t-test is lower than the significance level, then the correlation between variables is statistically significant (Lancaster \& Hamdan, 1964). The student's t-test is also applied to verify the statistical significance of regression coefficient estimates. The regression coefficient in the regression model is statistically significant if the p-value of the t-test is lower than the level of significance (Zheng $\& \mathrm{Yu}, 2015)$. In this paper, a significance level of $(\alpha) 5 \%$ applies to all calculations. The general LRM shape which indicates the impact of independent variables on the dependent variable, can be formulated into a regression function:

$$
B P=\beta_{0}+\beta_{1} \times S T_{1}+\beta_{2} \times S T_{2}+\ldots+\beta_{n} \times S T_{n}+\varepsilon_{n},
$$

where: $B P$ - dependent variable (perception of the future of $S M E s) ; \beta_{0}$ - constant, $\beta_{1} ; \ldots ; \beta_{n}$ - independent variable coefficient; $S T_{1}, \ldots, S T_{n}-$ independent variables (business risks); $\varepsilon_{n}$ - random component.

The quality of the regression model is determined by calculating and interpreting regression characteristics such as coefficient of determination, adjusted coefficient of determination, F-ratio, multicolinearity, normality of errors (Breslow, 1990). The coefficient of determination $\left(\mathrm{R}^{2}\right)$ indicates the percentage of explanation of the variability of the dependent variable, which can be explained by the chosen regression model (Lancaster \& Hamdan, 1964). The F-test was used to verify the statistical significance of the whole regression model (de Waal, 1977).

The required $\mathrm{p}$-value of the F-test must be lower than the significance level if we are to claim that the regression model is statistically significant. The assumption of multicolinearity in the regression model is verified using the inflation coefficient (VIF - test) (Liao et al., 2012). If the value of the VIF test for an independent variable is less than 5 , then this coefficient is not influenced by multicolinearity (Arnold, 1977). The Durbin-Watson test (D-W test) is used to verify that random components are not linearly dependent on each other (autocorrelation; Stewart, 1987). Autocorrelation is investigated if the sample data set is a time series. Due to the structure and nature of the data from the respondent samples, the verification of autocorrelation is not subject to investigation. The Shapiro-Wilk test (S-W test) was applied to verify the normal distribution of errors (de Waal, 1977).

This regression model assumption is accepted when the p-value of the $\mathrm{S}-\mathrm{W}$ test criterion is higher than the level of significance. The Bartlett test was used to verify the presumption of homoscedasticity. This assumption is accepted if the p-value of the Bartlett test criterion is higher than the level of significance.

The demographic structure of respondents who completed the questionnaire (before pandemic/during pandemic - 454/360: size of enterprise: 290/171 (63.9\%/47.5\%) micro-enterprise (up to 9 employees), $107 / 75(23.6 \% / 20.8 \%)$ small enterprise (10 to 49 employees), 57/114 (12,5\%/31,7\%) medium-sized enterprise (50 to 249 employees); legal form of enterprise: $135 / 152$ self-employed $(29.7 \% / 42.2 \%$ ), 266/116 (58.6\%/32.2\%) limited liability company, 34/63 (7.5\%/17.5\%) joint stock company, 19/29 $(4.2 \% / 8.1 \%)$ other type of legal form (co-op, v. o. s., o. p. s.); national business sector: $133 / 88$ $(29.3 \% / 24.4 \%)$ services, $91 / 83(20.1 \% / 23.1 \%)$ trade, $79 / 61(17.4 \% / 16.9 \%)$ production, $63 / 35$ $(13.9 \% / 9.7 \%)$ construction, $11 / 14(2,4 \% / 3,9 \%)$ tourism, $11 / 5(2.4 \% / 1.4 \%)$ agriculture, $10 / 20(5.6 \%)$ transportation, 56/54 (12.3\%/15.0\%) other area of business; time period of activity of the SME in the business environment: 55/112 (12.1\%/31.1\%) entrepreneurship up to 5 years, $64 / 65(14.1 \% / 18.1 \%)$ entrepreneurship from 6 to 10 years, 335/183 (73.8\%/50.8\%) entrepreneurship more than 10 years; the highest attained education level of the respondent: 46/51 (10.1\%/14.2\%) high school without diploma, 185/184 (40.8\%/51.1\%) high school with diploma, 34/42 (7.5\%/11.7\%) Bachelor's degree, 168/66 (37.0\%/18.3\%) Master's/Engineering degree, 21/17 (4.6\%/4.7\%) Doctoral higher education; gender of the respondent: $323 / 181$ male $(71.1 \% / 50.3 \%), 131 / 179(28.9 \% / 49.7 \%)$ female; age of the respondent: $69 / 118(15.2 \% / 32.8 \%)$ age up to 35 years, $106 / 109(23.3 \% / 30.3 \%)$ aged $36-45$ years, $122 / 71$ $(26.9 \% / 19.7 \%)$ aged 46 - 55 years, $157 / 62(34.6 \% / 17.2 \%)$ age higher than 55 years; work position in the 
INTERNATIONAL JOURNAL OF ENTREPRENEURIAL KNOWLEDGE

Issue 9, volume 2, ISSN 2336-2960 (Online)

www.ijek.org

company: $100 / 172(22.0 \% / 47.8 \%)$ owner of the business; $354 / 188(78.0 \% / 52.2 \%)$ manager of the business.

\section{RESULTS}

3.1 Assessment of the impact of business risks on the future of SMEs according to respondents before the COVID-19 pandemic

The results of the selected location characteristics and variability of the examined variables are subject of Table 2.

Table 2 Results of descriptive statistics - sample of respondents before the COVID-19 pandemic

\begin{tabular}{|c|c|c|c|c|c|c|}
\hline \multirow{2}{*}{ OCH } & ZP & \multicolumn{5}{|c|}{ NP - business risks } \\
\cline { 2 - 7 } & BP & ST1 & ST2 & ST3 & ST4 & ST5 \\
\hline $\mathbf{N}$ & 454 & 454 & 454 & 454 & 454 & 454 \\
\hline $\mathbf{C H H}$ & 0 & 0 & 0 & 0 & 0 & 0 \\
\hline SH & 2.238 & 2.458 & 2.564 & 2,231 & 2.121 & 2.678 \\
\hline SO & 1.116 & 1.022 & 1.085 & 0.989 & 0.907 & 1.140 \\
\hline ŠP & -0.053 & 0.114 & -0.524 & 0.406 & 0.627 & -0.587 \\
\hline ŠI & 0.735 & 0.625 & 0.340 & 0.776 & 0.741 & 0.448 \\
\hline MIN & 1 & 1 & 1 & 1 & 1 & 1 \\
\hline MAX & 5 & 5 & 5 & 5 & 5 & 5 \\
\hline
\end{tabular}

Notes: OCH - Description characteristics; $\mathrm{N}$ - Total number of respondents; NP - independent variable; ZP - dependent variable; $\mathrm{CHH}$ - Missing values; SH - Mean value; SO - Standard deviation; ŠP - Kurtosis; ŠI - Skewness; MIN - Minimum value; MAX - Maximum value.

(Source: Own data collection)

The results (See Table 2) showed that before the pandemic, the respondents most agree with the financial risk claim (ST4: $\mathrm{SH}=2.121)$. They least agree with the personnel risk claim (ST5: SH = 2.678). The results also show that the smallest variability (best consistency) of responses is to the ST4 claim ( $\mathrm{SO}=$ 0.907). On the contrary, the greatest variability of responses is to claim ST5 (SO = 1.140), followed by the $\mathrm{BP}$ claim $(\mathrm{SO}=1.116)$.

The paired coefficients of dependency between the examined business risk claims (independent variables - ST1, ST2, ST3, ST4, ST5) and the claim on the future of the business (dependent variable - BP) according to the respondents in the pre-pandemic data collection are summarized in a correlation matrix (Table 3).

Table 3 Correlation matrix of dependencies - sample of respondents before the COVID-19 pandemic

\begin{tabular}{|c|c|c|c|c|c|c||}
\hline KM & BP & ST1 & ST2 & ST3 & ST4 & ST5 \\
\hline BP & 1 & & & & & \\
\hline ST1 & $\begin{array}{c}0.306 \\
(0.000)^{*}\end{array}$ & 1 & & & & \\
\hline ST2 & $\begin{array}{c}0.102 \\
(0.043)^{*}\end{array}$ & $\begin{array}{c}0.183 \\
(0.000)^{*}\end{array}$ & 1 & & & \\
\hline
\end{tabular}


INTERNATIONAL JOURNAL OF ENTREPRENEURIAL KNOWLEDGE

Issue 9, volume 2, ISSN 2336-2960 (Online)

www.ijek.org

\begin{tabular}{|c|c|c|c|c|c|c|}
\hline \multirow{2}{*}{ ST3 } & $\begin{array}{c}0.409 \\
(0.000)^{*}\end{array}$ & $\begin{array}{c}0.431 \\
(0.000)^{*}\end{array}$ & $\begin{array}{c}0.259 \\
(0.000)^{*}\end{array}$ & 1 & & \\
\hline \multirow{2}{*}{ ST4 } & $\begin{array}{c}0.205 \\
(0.000)^{*}\end{array}$ & $\begin{array}{c}0.257 \\
(0.000)^{*}\end{array}$ & $\begin{array}{c}0.173 \\
(0.000)^{*}\end{array}$ & $\begin{array}{c}0.406 \\
(0.000)^{*}\end{array}$ & 1 & \\
\hline \multirow{2}{*}{ ST5 } & 0.155 & 0.111 & $\begin{array}{c}0.222 \\
(0.000)^{*}\end{array}$ & $\begin{array}{c}0.243 \\
(0.000)^{*}\end{array}$ & $\begin{array}{c}0.281 \\
(0.000)^{*}\end{array}$ & 1 \\
\hline
\end{tabular}

Notes: BP - dependent variable; ST1, ST2, ST3, ST4, ST5 - independent variables; KM - Correlation matrix; ${ }^{*}$ Statistically significant $\alpha=5 \%$.

(Source: Own data collection)

The results of the correlation matrix (see Table 3) show that all paired correlation coefficients are statistically significant for $\alpha$. Dependencies between selected claims on business risks (independent variables) are in the range $<0.111 ; 0.431>$. These values of paired correlation coefficients represent weak to moderate positive dependencies. The greatest positive dependency between independent variables can be observed between financial risk claims (ST3 and ST1; $r=0.431$ ). Dependencies between the dependent variable (BP) and independent variables (ST1, ST2, ST3, ST4 and ST5) are in the range $<0.102 ; 0.409>$. The greatest positive dependency is between the perception of the future of the business and the ST3 claim on financial risk $(r=0.409)$.

Due to the statistically significant dependence between variables, step-by-step regression analysis will be applied to find casual relationships (see Table 4).

Table 4 Linear regression model (LRM1) - sample of respondents before the COVID-19 pandemic

\begin{tabular}{|c|c|c|c|c|c|}
\hline \multicolumn{6}{|c|}{ Regression characteristics of the model } \\
\hline \multicolumn{4}{|c|}{ Multiple correlation coefficient } & \multicolumn{2}{|c|}{0.419} \\
\hline \multicolumn{4}{|c|}{ Coefficient of determination } & \multicolumn{2}{|c|}{0.175} \\
\hline \multicolumn{4}{|c|}{ Adjusted coefficient of determination } & \multicolumn{2}{|c|}{0.166} \\
\hline \multicolumn{4}{|c|}{ Mean value error } & \multicolumn{2}{|c|}{1.019} \\
\hline \multicolumn{4}{|c|}{ Total number of respondents } & \multicolumn{2}{|c|}{454} \\
\hline \multicolumn{6}{|c|}{ Verification of the statistical significance of the whole LRM1 } \\
\hline $\begin{array}{l}\text { Variability } \\
\text { source }\end{array}$ & $\begin{array}{l}\text { Number of degrees of } \\
\text { freedom }\end{array}$ & $\begin{array}{c}\text { Sum of variance } \\
\text { squares }\end{array}$ & $\begin{array}{c}\text { Mean } \\
\text { of } \\
\text { squares }\end{array}$ & \multicolumn{2}{|c|}{ F- ratio } \\
\hline Regression & 5 & 98.991 & 19.798 & \multicolumn{2}{|c|}{19.061} \\
\hline Residues & 448 & 465.317 & 1.039 & \multicolumn{2}{|c|}{$\mathrm{P}$ - value } \\
\hline Total & 453 & 564.308 & & \multicolumn{2}{|c|}{$3.32 \mathrm{E}-17$} \\
\hline \multicolumn{6}{|c|}{ Testing of the statistical significance of regression coefficients } \\
\hline Variables & $\begin{array}{c}\text { Regression } \\
\text { coefficient estimate }(\beta)\end{array}$ & Mean value error & t-Stat & $\begin{array}{c}\mathrm{t}-\mathrm{Stat} \\
(\mathrm{p}- \\
\text { value })\end{array}$ & $\begin{array}{l}\text { VIF } \\
\text { value }\end{array}$ \\
\hline Constant & 0.906 & 0.184 & 4.916 & 0.000 & - \\
\hline ST1 & 0.199 & 0.052 & 3.843 & $0.000^{*}$ & 1.22 \\
\hline ST2 & -0.027 & 0.047 & -0.580 & 0.562 & 1.12 \\
\hline ST3 & 0.327 & 0.058 & 5.659 & $0.000^{*}$ & $\begin{array}{c}1.42 \\
4\end{array}$ \\
\hline
\end{tabular}


INTERNATIONAL JOURNAL OF ENTREPRENEURIAL KNOWLEDGE

Issue 9, volume 2, ISSN 2336-2960 (Online)

www.ijek.org

\begin{tabular}{|c|c|c|c|c|c|}
\hline ST4 & 0.034 & 0.060 & 0.564 & 0.573 & $\begin{array}{c}1.27 \\
9\end{array}$ \\
\hline ST5 & 0.042 & 0.045 & 0.920 & 0.358 & $\begin{array}{c}1.15 \\
5\end{array}$ \\
\hline
\end{tabular}

Notes: t-Stat - Value of the student's testing criterion; ${ }^{*}$ Statistically significant regression coefficient $\alpha=5 \%$.

(Source: Own data collection)

The results (See Table 4) show that the proposed regression model of linear relationships (LRM1) between the examined variables is statistically significant (F-ratio: $\mathrm{p}$-value $=3.32 \mathrm{E}-17)$. The dependence between the perception of the future of the business and the examined business risks is moderately positive (Multiple correlation coefficient $=0.419$ ). LRM1 with proposed independent variables explains $16.6 \%$ (adjusted coefficient of determination $=0.166$ ) of variability of the dependent variable. Verification of the significance of regression coefficients confirmed the statistical significance of independent variables: ST1 (t-Stat p-value $=0.000)$ and ST3 (t-Stat p-value $=0.000)$. On the other hand, the statistical significance of independent variables is rejected at the significance level: ST2 (t-Stat p-value $=0.562)$ and ST4 $(\mathrm{t}-\mathrm{Stat} \mathrm{p}$-value $=0.573)$ and ST5 $(\mathrm{t}-\mathrm{Stat} \mathrm{p}$-value $=0.358)$. The proposed regression model with linear trend has the following regression function (LRM1) shape:

$$
\boldsymbol{B P}=0.906+0.199 \times \boldsymbol{S T 1}-0.027 \times S T 2+0.327 \times \boldsymbol{S T 3}+0.034 \times S T 4+0.042 \times S T 5+\varepsilon_{t,} \quad(2)
$$

where: BP - dependent variable (the future of SMEs); ST1, ST2, ST3, ST4, ST5 - independent variables (business risk claims); $\varepsilon_{t}-$ random component.

The VIF test values did not show the presence of multicolinearity in independent variables (ST3 has the highest VIF value $=1.424)$. Homoscedasticity was confirmed in LRM1 (Bartlett's test: p-value $=0.182)$. The normal distribution of deviations of random components was confirmed by the S-W test (S-W test: $\mathrm{p}$-value $=0.354$ ). Based on the above statistical results, it is not possible to reject the statistical hypotheses

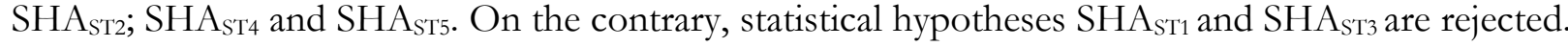

\subsection{Assessment of the impact of business risks on the future of SMEs according to respondents} during the COVID-19 pandemic

The results of selected location characteristics and variability of examined variables are subject of Table 5.

Table 5 Results of descriptive statistics - sample of respondents during the COVID-19 pandemic

\begin{tabular}{|c|c|c|c|c|c|c|}
\hline \multirow{2}{*}{ OCH } & ZP & \multicolumn{5}{|c|}{ NP - business risks } \\
\cline { 2 - 7 } & BP & ST1 & ST2 & ST3 & ST4 & ST5 \\
\hline $\mathbf{N}$ & 360 & 360 & 360 & 360 & 360 & 360 \\
\hline $\mathbf{C H H}$ & 0 & 0 & 0 & 0 & 0 & 0 \\
\hline SH & 2.456 & 2.608 & 2.656 & 2.722 & 2.431 & 2.539 \\
\hline SO & 1.088 & 1.007 & 0.972 & 1.026 & 0.896 & 0.984 \\
\hline ŠP & -0.278 & -0.665 & -0.234 & -0.537 & 0.402 & 0.042 \\
\hline ŠI & 0.584 & 0.483 & 0.480 & 0.453 & 0.700 & 0.641 \\
\hline MIN & 1 & 1 & 1 & 1 & 1 & 1 \\
\hline MAX & 5 & 5 & 5 & 5 & 5 & 5 \\
\hline
\end{tabular}

Notes: OCH - Descriptive characteristics; N - Total number of respondents; NP - Independent variable; ZP - Dependent variable; $\mathrm{CHH}$ - Missing values; $\mathrm{SH}$ - Mean value; SO - Standard deviation; ŠP - Kurtosis; ŠI - Skewness; MIN - Minimum value; MAX - Maximum value. 
INTERNATIONAL JOURNAL OF ENTREPRENEURIAL KNOWLEDGE

Issue 9, volume 2, ISSN 2336-2960 (Online)

www.ijek.org

(Source: Own data collection)

The results (see Table 5) showed that before the pandemic, the respondents most agree with the financial risk claim (ST4: $\mathrm{SH}=2.431)$. The least agree with the ST3 claim $(\mathrm{SH}=2.722)$. The results also show that the smallest variability (best consistency) of responses is to claim ST4 (SO $=0.896)$. On the contrary, the greatest variability of responses is to the BP claim $(\mathrm{SO}=1.088)$, followed by claim ST1 ( $\mathrm{SO}=1.007$ ). The paired coefficients of dependency between the examined business risk claims (independent variables - ST1, ST2, ST3, ST4, ST5) and the claim about the future of the business (dependent variable - BP), according to the respondents during the data collection during the pandemic are summarized in the correlation matrix (Table 6).

Table 6 Correlation matrix of dependencies - sample of respondents during the COVID-19 pandemic

\begin{tabular}{|c|c|c|c|c|c|c||}
\hline KM & BP & ST1 & ST2 & ST3 & ST4 & ST5 \\
\hline BP & 1 & & & & & \\
\hline ST1 & $\begin{array}{c}0.207 \\
(0.000)^{*}\end{array}$ & 1 & & & & \\
\hline ST2 & $\begin{array}{c}0.267 \\
(0.000)^{*}\end{array}$ & $\begin{array}{c}0.249 \\
(0.000)^{*}\end{array}$ & 1 & & & \\
\hline ST3 & $\begin{array}{c}0.323 \\
(0.000)^{*}\end{array}$ & $\begin{array}{c}0.372 \\
(0.000)^{*}\end{array}$ & $\begin{array}{c}0.367 \\
(0.000)^{*}\end{array}$ & 1 & & \\
\hline ST4 & $\begin{array}{c}0.295 \\
(0.000)^{*}\end{array}$ & $\begin{array}{c}0.289 \\
(0.000)^{*}\end{array}$ & $\begin{array}{c}0.315 \\
(0.000)^{*}\end{array}$ & $\begin{array}{c}0.506 \\
(0.000)^{*}\end{array}$ & 1 & \\
\hline ST5 & 0.296 & $\begin{array}{c}0.315 \\
(0.006)^{*}\end{array}$ & $\begin{array}{c}0.221 \\
(0.000)^{*}\end{array}$ & $\begin{array}{c}0.383 \\
(0.000)^{*}\end{array}$ & $\begin{array}{c}0.384 \\
(0.000)^{*}\end{array}$ & 1 \\
\hline \hline
\end{tabular}

Notes: BP - dependent variable; ST1, ST2, ST3, ST4, ST5 - independent variables; KM - Correlation matrix; ${ }^{*}$ Statistically significant $\alpha=5 \%$.

(Source: Own data collection)

The results of the correlation matrix (see Table 6) show that all paired correlation coefficients are statistically significant for $\alpha$. Dependencies between selected claims on business risks (independent variables) are in the range $<0.221 ; 0.506>$. These values of paired correlation coefficients represent weak to moderate positive dependencies. The greatest positive dependency between independent variables can be observed between financial risk claims (ST3 and ST4; $r=0.406$ ). Dependencies between the dependent variable (BP) and independent variables (ST1, ST2, ST3, ST4, and ST5) are in the <0.207; $0.323>$ interval. The greatest positive dependency is between the perception of the future of the business and ST3 claim on financial risk $(\mathrm{r}=0.323)$.

Due to the statistically significant dependence between variables, a step-by-step regression analysis will be applied to find causal relationships (see Table 7).

Table 7 Linear regression model (LRM2) - sample of respondents during the COVID-19 pandemic

\begin{tabular}{|c|c|}
\hline \multicolumn{2}{|c|}{ Regression characteristics of the model } \\
\hline Multiple correlation coefficient & 0.411 \\
\hline Coefficient of determination & 0.169 \\
\hline
\end{tabular}


INTERNATIONAL JOURNAL OF ENTREPRENEURIAL KNOWLEDGE

Issue 9, volume 2, ISSN 2336-2960 (Online)

www.ijek.org

\begin{tabular}{|c|c|c|c|c|c|}
\hline \multicolumn{4}{|c|}{ Adjusted coefficient of determination } & \multicolumn{2}{|c|}{0.157} \\
\hline \multicolumn{4}{|c|}{ Mean value error } & \multicolumn{2}{|c|}{0.999} \\
\hline \multicolumn{4}{|c|}{ Total number of respondents } & \multicolumn{2}{|c|}{360} \\
\hline \multicolumn{6}{|c|}{ Verification of the statistical significance of the whole LRM1 } \\
\hline $\begin{array}{l}\text { Variability } \\
\text { source }\end{array}$ & $\begin{array}{l}\text { Number of degrees of } \\
\text { freedom }\end{array}$ & $\begin{array}{c}\text { Sum of variance } \\
\text { squares }\end{array}$ & $\begin{array}{c}\text { Mean } \\
\text { of } \\
\text { squares }\end{array}$ & \multicolumn{2}{|c|}{ F- ratio } \\
\hline Regression & 5 & 71.915 & 14.383 & \multicolumn{2}{|c|}{14.409} \\
\hline Residuals & 354 & 353.374 & 0.998 & \multicolumn{2}{|c|}{$\mathrm{P}$ - value } \\
\hline Total & 359 & 425.289 & & \multicolumn{2}{|c|}{$7.47 \mathrm{E}-13$} \\
\hline \multicolumn{6}{|c|}{ Testing of the statistical significance of regression coefficients } \\
\hline Variables & $\begin{array}{c}\text { Regression } \\
\text { coefficient estimate }(\beta)\end{array}$ & Mean value error & t-Stat & $\begin{array}{c}\mathrm{t}-\text { Stat } \\
(\mathrm{p}- \\
\text { value })\end{array}$ & $\begin{array}{l}\text { VIF } \\
\text { value }\end{array}$ \\
\hline Constant & 0.767 & 0.213 & 3.609 & 0.000 & - \\
\hline ST1 & 0.042 & 0.058 & 0.716 & 0.475 & $\begin{array}{c}1.23 \\
1\end{array}$ \\
\hline ST2 & 0.152 & 0.060 & 2.560 & $0.011^{*}$ & $\begin{array}{c}1.20 \\
3\end{array}$ \\
\hline ST3 & 0.153 & 0.064 & 2.369 & $0.018^{*}$ & $\begin{array}{c}1.57 \\
2\end{array}$ \\
\hline ST4 & 0.142 & 0.071 & 2.002 & $0.048^{*}$ & $\begin{array}{c}1.46 \\
1\end{array}$ \\
\hline ST5 & 0.173 & 0.061 & 2.853 & $0.005^{*}$ & $\begin{array}{c}1.28 \\
5\end{array}$ \\
\hline
\end{tabular}

Notes: t-Stat - value of student's testing criterion; ${ }^{*}$ Statistically significant regression coefficient $\alpha=5 \%$.

(Source: Own data collection)

The results (see Table 7) show that the proposed regression model of linear relationships (LRM2) between the examined variables is statistically significant (F-ratio: $\mathrm{p}$-value $=7.47 \mathrm{E}-13)$. The dependence between the perception of the future of the business and the examined business risks is moderately positive (Multiple correlation coefficient $=0.411$ ). LRM2 with proposed independent variables explains $15.7 \%$ (adjusted coefficient of determination $=0.157$ ) of variability of the dependent variable. Verification of the significance of regression coefficients confirmed the statistical significance of independent variables: ST2 $(\mathrm{t}-\mathrm{Stat} \mathrm{p}$-value $=0.011) ; \mathrm{ST} 3(\mathrm{t}-\mathrm{Stat} \mathrm{p}$-value $=0.018) ; \mathrm{ST} 4(\mathrm{t}-\mathrm{Stat} \mathrm{p}$-value $=$ $0.048)$ and ST5 (t-Stat p-value $=0.005)$. On the other hand, the statistical significance of independent variables is rejected at the significance level: ST1 ( $\mathrm{t}$-Stat $\mathrm{p}$-value $=0.475)$. The proposed regression model with linear trend has the following regression function (LRM2) shape:

$$
\boldsymbol{B P}=0.767+0.042 \times S T 1+0.152 \times S T 2+0.153 \times S T 3+0.142 \times S T 4+0.173 \times S T 5+\varepsilon_{t},
$$

where: BP - dependent variable (future of SME); ST1, ST2, ST3, ST4, ST5 - independent variables (business risk claims); $\varepsilon_{t}$ - random component.

The VIF test values did not show the presence of multicolinearity in independent variables (ST3 has the highest VIF value $=1,572$ ). Homoscedasticity was confirmed in LRM2 (Bartlett's test: $\mathrm{p}$-value $=0.174$ ). The normal distribution of deviations of random components was confirmed by the S-W test (S-W test: $\mathrm{p}$-value $=0,488)$. Based on the above statistical results, the statistical hypothesis of SHBST1 cannot be rejected. On the contrary, statistical hypotheses of SHBST2; SHBST3; SHBST4 and SHBST5 are rejected. 


\section{INTERNATIONAL JOURNAL OF ENTREPRENEURIAL KNOWLEDGE}

Issue 9, volume 2, ISSN 2336-2960 (Online)

www.ijek.org

\section{DISCUSSION}

The results of the correlation analysis showed the statistical significance of all pair coefficients between the examined variables in the sample of respondents during the pre-pandemic and pandemic data collection periods. Moderate positive dependence was manifested between the perception of the financial performance of the enterprise and the future of the enterprise/business $(r=0.409 ; \mathrm{p}$-value $=0.000)$ according to the sample of respondents before the pandemic. On the other hand, there were weak positive links between the perception of the financial performance of the company and the future of the company $(\mathrm{r}=0.323$; $\mathrm{p}$-value $=0.000)$ according to the sample of respondents during the pandemic. The finding of a correlation analysis is that a positive perception of the financial performance of the enterprise will be reflected in a positive perception of the future of SMEs.

Paired dependencies between the most significant business risks showed rather weak to moderate values, regardless of the selected sample of respondents. Moderate positive dependence was manifested among financial risk indicators (note the strongest dependency between independent variables; $\mathrm{n}=360$ ). Namely, between the financial performance of the enterprise and the ability to manage financial risk appropriately $(\mathrm{r}=0.506)$ in the sample of respondents during the period of data collection during the pandemic. The moderate positive dependency is between the financial performance of the enterprise and the perception of the lack of sales of the enterprise $(r=0.431$; note the strongest dependency between independent variables; $\mathrm{n}=454)$.

The linear regression model (LRM1) demonstrated a statistically significant impact on the future of SMEs due to the adequacy of the company's sales $(p$-value $=0.000)$ and the financial performance of the enterprise $(p$-value $=0.000)$. On the contrary, statistically significant impact: $i$. innovative ways to acquire new markets and retain existing customers $(\mathrm{p}$-value $=0.562)$; ii. ability to manage financial risk appropriately ( $\mathrm{p}$-value $=0,573)$; iii. the adequacy of personnel risk in the enterprise $(\mathrm{p}$-value $=0.358)$ for the perceived future of SMEs was not confirmed. The impact of the adequacy of the company's sales $(\beta$ $=0.199)$ on the future of SMEs is less than the financial performance of the enterprise $(\beta=0.327)$ according to respondents during the pre-pandemic data collection period.

The linear regression model (LRM2) has demonstrated a statistically significant impact: i. innovative ways to acquire new markets and retain existing customers ( $\mathrm{p}$-value $=0.011$ ); ii. ability to manage financial risk appropriately ( $\mathrm{p}$-value $=0.018$ ); iii. the financial performance of the enterprise ( $\mathrm{p}$-value $=0.048$ ); iv. adequacy of personnel risk in the enterprise $(p$-value $=0.005)$ for the future of SMEs (there is no risk of decline within the horizon of 5 years). On the contrary, the statistically significant impact of the adequacy of the company's sales ( $\mathrm{p}$-value $=0.475$ ) on the perceived future of SMEs was not confirmed according to respondents during the period of data collection during the pandemic. The adequacy of personnel risk in the enterprise $(\beta=0.173)$ has the strongest impact on the positive perception of the future of SMEs. There is statistically significant impact of also: i. financial performance of the enterprise $(\beta=0.153)$; ii. innovative ways of acquiring new markets and retaining existing customers $(\beta=0.152)$ and the impact of the ability to manage financial risk appropriately $(\beta=0.142)$. The above claims on business risks positively determine the positive perception of the future of SMEs according to respondents during the pre-pandemic data collection period.

In this context, it is interesting to observe the study by Dvoulety \& Orel (2021) whose aim was to assess the impact of investment grants on the financial performance of Czech companies in regards to their size. The partial aim of the study was to determine whether the supported large enterprises showed better financial results compared to SMEs two years after providing the grant. The results of the study confirmed that the size of the company played a significant role in the financial performance of the businesses who received grants between 2007 and 2013 from the Operational Program of Entrepreneurship and Innovation (OPPI). While microenterprises managed to demonstrate an 


\section{INTERNATIONAL JOURNAL OF ENTREPRENEURIAL KNOWLEDGE}

Issue 9, volume 2, ISSN 2336-2960 (Online)

www.ijek.org

improvement of financial performance two years after the end of the program in virtually all result indicators, large companies failed to demonstrate an increase of competitiveness. Dvoulety \& Orel (2021) also suggest that business support policymakers allocate public funds to SMEs who are more likely to increase their competitiveness than large enterprises.

\section{CONCLUSIONS}

The article aimed to identify, analyze, and quantify differences in the impact of entrepreneurial risks on the future of SMEs in the business environment of the Czech Republic in light of the COVID-19 pandemic.

In the segment of small and medium-sized enterprises of the business environment in the Czech Republic, the COVID-19 pandemic showed significant differences in the impact of the most important business risks on the future of SMEs. Prior to the COVID-19 pandemic, entrepreneurs were found to see the adequacy of sales and the business's financial performance as key determinants impacting the future of SMEs on a 5-year horizon. On the contrary, during the COVID-19 pandemic, entrepreneurs perceived the management of personnel risk, the financial performance of the business, and the ability to manage financial risk as determinants impacting the future of SMEs in a 5-year horizon.

The achieved results are primarily intended for the business environment in the Czech Republic, which, due to its size, is only of local importance. The subjectivity of top managers' and owners' attitudes is primarily influenced by a number of factors (e.g.: SMEs' financial performance); however, it is important to present primary research findings. The paper's findings are intended primarily for SME owners and top managers. The findings are important for governmental and non-governmental organizations as a basis for decision-making and the creation of strategic documents. The findings may also benefit nonprofit associations that help improve the quality of the business environment or the SMEs themselves.

In the future, the authors will focus on comparing the findings of the SME segment in the business environment of the Czech Republic with the business environment of the SME segment in Slovakia, given the available data and the similarity of the business environment in selected Central European countries.

\section{REFERENCES}

Alves, J.C., Lok, T.CH., Luo, Y.B., Hao, W. (2020). Crisis Management for Small Business during the COVID-19 Outbreak: Survival, Resilience and Renewal Strategies of Firms in Macau. Research Swuare, 1 - 29. https://doi.org/10.21203/rs.3.rs-34541/v1

Åslund, A. (2020). Responses to the COVID-19 crisis in Russia, Ukraine, and Belarus. Eurasian Geography and Economics, 61(4-5), 532-545. https://doi.org/10.1080/15387216.2020.1778499

Belas, J., Amoah, J., Petráková, Z., Kliuchnikava, Y., Bilan, Y. (2020). Selected Factors of SMEs Management in the Service Sector. Journal of Tourism and Services, 21(11), 129-146. https://doi.org/10.29036/jots.v11i21.215

Breslow, N. (1990). Tests of hypotheses in overdispersed poisson regression and other quasi-likelihood models. Journal of the American Statistical Association, 85(410), 565-571. https://doi.org/10.1080/01621459.1990.10476236

Cepel, M., Gavurova, B., Dvorsky, J., \& Belas, J. (2020). The impact of the covid-19 crisis on the perception of business risk in the SME segment. Journal of International Studies, 13(3), 248-263. https://doi.org/10.14254/2071-8330.2020/13-3/16 


\section{INTERNATIONAL JOURNAL OF ENTREPRENEURIAL KNOWLEDGE}

Issue 9, volume 2, ISSN 2336-2960 (Online)

www.ijek.org

Civelek, M., Gajdka, K., Světlík, J., \& Vavrečka, V. (2020). Differences in the usage of online marketing and social media tools: evidence from Czech, Slovakian and Hungarian SMEs. Equilibrium. Quarterly Journal of Economics and Economic Policy, 15(3), 537-563. https://doi.org/10.24136/eq.2020.024

Civelek, M., Ključnikov, A., Fialova, V., Folvarčná, A., \& Stoch, M. (2021). How innovativeness of familyowned SMEs differ depending on their characteristics? Equilibrium. Quarterly Journal of Economics and Economic Policy, 16(2), 239-252. doi: https://doi.org/10.24136/eq.2021.015

Core, F. \& De Marco, F. (2021). Public Guarantees for Small Businesses in Italy during COVID-19. 152. http://dx.doi.org/10.2139/ssrn.3604114

Dvorský, J., Petráková, Z., Fialová, V. (2020). Perception of Business Risks by Entrepreneurs According to Experience with the Business Failure. International Journal of Entrepreneurial Knowledge, 8(1), 76-88. https://doi.org/10.37335/ijek.v8i1.104

Dvoulety, O., \& Orel, M. (2020). Determinants of solo and employer entrepreneurship in Visegrád countries: Findings from the Czech Republic, Hungary, Poland and Slovakia. Journal of Enterprising Communities, 14(3), 447-464. https://doi.org/10.1108/JEC-04-2020-0052

Fontrodona, J., \& Muller, P. (2020). Strengthening Business Integrity in the Face of the COVID-19 Crisis. IESE Business School Working, OP-333,1-12. http://dx.doi.org/10.2139/ssrn.3571706

Ganlin, P., Qamruzzaman, M. D., Mehta, A. M., Naqvi, F. N., \& Karim, S. (2021). Innovative finance, technological adaptation and SMEs sustainability: The mediating role of government support during covid-19 pandemic. Sustainability (Switzerland), 13(16) https://doi.org/10.3390/su13169218

Godany, Z., \& Mura, L. 2021. Success from the perspective of female entrepreneurs. Entrepreneurship and Sustainability Issues, 9(2), 521-534. http://doi.org/10.9770/jesi.2021.9.2(34)

Grondys, K., Ślusarczyk, O., Hussain, H. I., \& Androniceanu, A. (2021). Risk assessment of the SME sector operations during the covid-19 pandemic. International Journal of Environmental Research and Public Health, 18(8). https://doi.org/10.3390/ijerph18084183

Hoeft, F. (2021). The case of sales in the automotive industry during the COVID-19 pandemic. Strategic Change, 30(2), 117-125. https://doi.org/10.1002/jsc.2395

Klein, V. B., \& Todesco, J. L. (2021). COVID-19 crisis and SMEs responses: The role of digital transformation. Knowledge and Process 117-133. https://doi.org/10.1002/kpm.1660

Ključnikov, A., Civelek, M., Fialova, V., \& Folvarčná, A. (2021). Organizational, local, and global innovativeness of family-owned SMEs depending on firm-individual level characteristics: evidence from the Czech Republic. Equilibrium. Quarterly Journal of Economics and Economic Policy, 16(1), 11-23. doi: 10.24136/eq.2021.006

Korauš, A., Havierniková, K., Gombár, M., Černák, F., \& Miroslav, F. (2020). Dimensions and their elements affecting the innovative activities of agricultural SMEs toward their sustainable development. Entrepreneurship and Sustainability Issues, 8(2), 1142-1157. https://doi.org/10.9770/jesi.2020.8.2(68)

Lancaster, H. O., \& Hamdan, M. A. (1964). Estimation of the correlation coefficient in contingency tables with possibly nonmetrical characters. Psychometrika, 29(4), 383-391. d https://doi.org/10.1007/BF02289604

Levashenko, A. \& Koval, A. (2020). Measures of Financial and Non-Financial Support to Small and Medium-sized Enterprises (SMEs) in the Wake of COVID-19. Monitoring of Russia's Economic Outlook. Trends and Challenges of Socio-economic Development, 9, 7-10. http://dx.doi.org/10.2139/ssrn.3629597

Liu, N., Xu, Z., \& Skare, M. (2021). The research on COVID-19 and economy from 2019 to 2020: analysis from the perspective of bibliometrics. Oeconomia Copernicana, 12(2), 217-268. https://doi.org/10.24136/oc.2021.009

Lu, Y., Wu, J., Peng, J., \& Lu, L. (2020). The perceived impact of the covid-19 epidemic: Evidence from a sample of 4807 SMEs in Sichuan province, China. Environmental Hazards, 19(4), 323-340. https://doi.org/10.1080/17477891.2020.1763902 


\section{INTERNATIONAL JOURNAL OF ENTREPRENEURIAL KNOWLEDGE}

Issue 9, volume 2, ISSN 2336-2960 (Online)

www.ijek.org

Machová, R., Korcsmáros, E., Esseová, M., Marča R. (2021). Changing Trends of Shopping Habits and Tourism During the Second Wave of COVID-19 - International Comparison. Journal of Tourism and Services, 22(12), 131-149. https://doi.org/10.29036/jots.v12i22.256

Miguel, A., Martinez-Bravo; M., SANZ, C. (2020). The Political Consequences of the Covid-19 Crisis. AEA RCT Registry. https://doi.org/10.1257/rct.6084-1.0

Mihai, L. (2021). Study regarding the leadership styles practiced in Catalan SMEs during the COVID-19 pandemic. IBIMA Business Review, 2021 https://doi.org/10.5171/2021.414966

Michie, J. (2020). The covid-19 crisis-and the future of the economy and economics. International Review of Applied Economics, 34(3), 301-303. https://doi.org/10.1080/02692171.2020.1756040

Mikołajczak, P. (2021). What affects employment by NGOs? counteraction to precarious employment in the polish non-profit sector in the perspective of COVID-19 pandemic crises. Oeconomia Copernicana, 12(3), 761-788. https://doi.org/10.24136/OC.2021.025

Morrison, E.R. \& Saavedra, A. (2020). Bankruptcy's Role in the COVID-19 Crisis. Columbia Law and Economics Working Paper, 624, 1 - 15. Available from: http://dx.doi.org/10.2139/ssm.3567127

Mura, L. \& Hajduová, Z. (2021). Measuring efficiency by using selected determinants in regional SMEs. Entrepreneurship and Sustainability Issues, 8 (3), 487-503. https://doi.org/10.9770/jesi.2021.8.3(31)

Niciejewska, M., Idzikowski, A., Škurková, K. L. (2021). Impact of technical, organizational and human factors on accident rate of small-sized enterprises. Management Systems in Production Engineering, 29(2), 139-144. https://doi.org/10.2478/mspe-2021-0018

Prohorovs, A. (2020). Getting Ready for Recession: How SMEs Prepared for Covid-19 Pandemic and Economic Recession. Forbes, 11, 46-49. http://dx.doi.org/10.2139/ssrn.3596611

Rai, J., Tripathi, R. C., \& Gulati, N. (2020). A comprehensive survey of IT sectors affected by covid-19. Paper presented at the Proceedings of the 2020 9th International Conference on System Modeling and Advancement in Research Trends, SMART 2020, 52-54. https://doi.org/10.1109/SMART50582.2020.9337132

Rathore, U., \& Khanna, S. (2020). From Slowdown to Lockdown: Effects of the COVID-19 Crisis on Small Firms in India. http://dx.doi.org/10.2139/ssrn.3615339

Redmond, P. \& Mcguinness, S. (2020). Essential Employees during the Covid-19 Crisis. The Economic and Social Research Institute. 1-10. https://www.esri.ie/system/files/publications/SUSTAT85 0 0.pdf

Rodrigues, M., Franco, M., Sousa, N., \& Silva, R. (2021). Covid 19 and the business management crisis: An empirical study in SMEs. Sustainability (Switzerland), 13(11) https://doi.org/10.3390/su13115912

Rozsa, Z., \& Machova, V. (2020). Factors Affecting Job Announcement Competitiveness on Job Listing Websites. Journal of Competitiveness, 12(4), 109-126. doi:10.7441/joc.2020.04.07

Spanos, A., \& McGuirk, A. (2002). The problem of near-multicollinearity revisited: Erratic vs systematic volatility. Journal of Econometrics, 108(2), 365-393. https://doi.org/10.1016/S0304-4076(01)00144-0

Virglerova, Z., Dvorsky, J., Kozubikova, L., \& Cepel, M. (2020). Perception of non-financial risk determinants in SMEs in visegrad countries. Oeconomia Copernicana, 11(3), 509-529. https://doi.org/10.24136/OC.2020.021

Zhou, R., Cai, Z., \& Shen, L. (2021). Study on the financing efficiency of SMEs under the epidemic situation of COVID-19 based on DEA-malmquist model. Paper presented at the ACM International Conference Proceeding Series, 143-147. https://doi.org/10.1145/3459012.3459035

de Waal, D. J. (1977). Asymptotic distributions for the elementary symmetric functions of two matrices under the assumption of linearity. Journal of Multivariate Analysis, 7(1), 223-228. https://doi.org/10.1016/0047-259X(77)90042-2

Wang, Y. (2016). What are the biggest obstacles to growth of SMEs in developing countries? - an empirical evidence from an enterprise survey. Borsa Istanbul Review, 16(3), 167-176. https://doi.org/10.1016/j.bir.2016.06.001

Wei, S., He, Y., Zhou, W., Popp, J., \& Oláh, J. (2021). Death reflection and employee work behavior in the covid-19 new normal time: The role of duty orientation and work orientation. Sustainability (Switzerland), 13(20) https://doi.org/10.3390/su132011174 
INTERNATIONAL JOURNAL OF ENTREPRENEURIAL KNOWLEDGE

Issue 9, volume 2, ISSN 2336-2960 (Online)

www.ijek.org

Zheng, M., \& Yu, W. (2015). Linear regression analysis with inequality constraints on the regression parameters via empirical likelihood. Journal of Statistical Computation and Simulation, 85(9), 1782-1792. https://doi.org/10.1080/00949655.2014.902459

\section{BRIEF DESCRIPTION OF AUTHOR/AUTHORS:}

Ing. Ján Dvorsky, PhD.

ORCID ID: https://orcid.org/0000-0002-6078-2636

Affiliation: Tomas Bata University in Zlín, Faculty of Management and Economics, Department of Business Administration, Mostní 5139, $760 \quad 01$ Zlín, Czech Republic, website: https://fame.utb.cz/en/department-of-enterprise-economics/about-the-department/

Email: j1dvorsky@utb.cz.

His research is focused on Enterprise Economics, Quality of Business Environment, Risk Management, Small and Medium-size Enterprise, and Education of students in the economic field. He published 45 scientific articles on database Scopus $($ h-index $=9)$.

\section{Dr. Martin Čepel, Ph.D., MBA, DBA}

ORCID ID: https://orcid.org/0000-0002-6282-9899

Affiliation: University of Entrepreneurship and Law, Department of Marketing, Spálená 76/14, 11000 Praha, Czech Republic, website: https://www.vspp-international.com/

Email: martin.cepel@vspp.cz

His research and research activities focus on SME entrepreneurship, the quality of business environment, entrepreneurial economics, financial risk management, business administration, administration, and marketing management. His publication portfolio comprises 49 articles and outputs of international scientific conferences registered in the WoS and Scopus databases. His HI is 9 (WoS/Scopus).

Ing. Anna Kotásková, PhD.

ORCID ID: https://orcid.org/0000-0001-7185-6541

Affiliation: University of Entrepreneurship and Law, Department of Marketing, Spálená 76/14, 11000 Praha, Czech Republic, website: https://www.vspp-international.com/

Email: anna.kotaskova@vspp.cz

Anna Kotaskova is an assistant professor at the University of Entrepreneurship and Law in Prague. Her research focuses on entrepreneurship with emphasis on SMEs' segment, the quality of the business environment for SMEs, SMEs financing and performance, business administration, as well as on macroeconomics in general. She has published more than 30 articles indexed in the Web of Science and Scopus databases. Her current H-index is 5 (WoS) or 6 (Scopus).

\section{Assoc. Prof. Katarína Buganová, PhD.}

ORCID ID: https://orcid.org/0000-0002-0596-5229

Affiliation: University of Žilina, Faculty of security engineering, Department of Crisis management, Univerzitná 8215/1, 010026 Žilina, Slovak republic, website: https://fbi.uniza.sk/en/pracoviska/kkm Email: katarina.buganova@fbi.uniza.sk

She is the Head of the Crisis Management Department. She teaches the subjects Risk management, Business Risks, Project Management, Management of Change, and Marketing. Her scientific activities cover the area of risk management in enterprises and projects, crisis management, and the systems of early warning in the framework of entrepreneurial activities. She attended several training courses on risk management, crisis management, and integrated quality management within her continuing education. She is a co-ordinator and a member of several research teams of domestic and European projects. She is 
INTERNATIONAL JOURNAL OF ENTREPRENEURIAL KNOWLEDGE

Issue 9, volume 2, ISSN 2336-2960 (Online)

www.ijek.org

the author of several university textbooks, scripts, domestic and foreign publications focused on risk management in enterprise. 